\title{
Discursive Construction of Language between the Vehicle Inspection Officers and Drivers in Abuja
}

\author{
Godwin AyigboOwojecho \\ Department of English, Institute of Education, University of Abuja, Abuja, Nigeria \\ tok2anglogodson@gmail.com
}

DOI: https://doi.org/10.36892/ijlls.v2i1.181

\section{Received:}

10/02/2020

Accepted:

$21 / 03 / 2020$

Keywords:

Discursive, IDF, VIO

\section{Abstract}

Language has, since, shifted from just being a means of communication to a manner of showcasing power, ideology and other fundamental issues of identity. This has been the result of the shift in focus from language analysis as a form to language analysis as a function by modern linguists. This work, basically, is an exploration into the discursive properties in the interlocutions of Vehicle Inspection Officers (VIOs) and drivers on the major highways in Abuja. Their conversations were sampled through oral interviews and participant observation. This was carried out at the VIO major offices in Abuja and three major highways: the Nyanya-Keffi highway, the Zuba-Kaduna highway, and the Gwagwalada-Lokoja highway. To properly unveil the invested ideology and the exercise of power, Fairclough's (1995) Ideological Discursive Formations (IDF) and Fairclough's (1989) Members Resources, with insights from van Dijk's (1998, 2001) social cognitive notion of Positive Self-presentation and Negative Other-presentation are employed. It is discovered that language is a veritable tool used by the officers and, sometimes, the drivers to perpetuate power and inherent ideology. The findings show that a lot of illegitimate dealings are committed by the Vehicle Inspection Officers and drivers as they deploy different strategies in words and action to display a superior ideology and institutional power.

\section{INTRODUCTION}

Language is described as a "human vocal noise or the arbitrary graphic representation of this noise, used systematically and conventionally by members of a speech community for purposes of communication" (Osisanwo, 2003, p.2). It is an integral part of human existence; a special attribute that distinguishes a human being from an animal. Essentially, language is for communication and communication usually requires an understanding of the connections between an utterance and the interlocutors (Amberge, 2009). Every speech situation, no doubt, dwells so much on language. As people interact from time to time, language is used to communicate information among them. The socio economic level of people, their social background and status, power and ideological identities are measured and evaluated by how they speak and interact. 
In any communication situation, language is a fundamental tool used to achieve an aim. Indeed, it is "used widely in various communication modes." (Gatcho \& Ramos, 2019, $\mathrm{p} 1$ ). It has been observed that when there is a conversation between two interlocutors, an implicit ideology is often manifested explicitly through the exercise of social power and ideology. These issues are mostly manifested when the conversation is held between a dominant socialactor (powerful groups) and a dominated social actor (dominated groups) in a certain social setting (Owojecho, 2017). The speech situation between the members of the Vehicle Inspection Office (VIO) and drivers on major highways in Abuja, FCT is a case in point. The Vehicle Inspection Office - Driver and Vehicle Licensing Administration (VIODVLA) is an office with the constitutional mandate of Motor Vehicle Administration Duty in Nigeria. They work in conjunction with the Federal Road Safety Corps (FRSC), a sister agency responsible for the safety of the road, the road users and vehicles plying the road. Their basic duties involve the inspection of private and commercial vehicles through the use of improved technology so as to ensure that all vehicles plying the road are certified road worthy. The VIO is also responsible for the issuance of drivers' license as well as test drivers' competence and check vehicles' particulars to ensure that motorists comply with the payment of road taxes. In the Federal Capital Territory, Abuja, the VIO is under the direct jurisdiction of the FCT minister. In line with national tax laws, road taxes generated by the VIO are payable to the state in which the office is resident.

Modern studies of language have shown that power and ideology are inherent in language when interlocutors interact. In this study, a Critical Discourse Analysis (also known as CDA) approach is taken to analyze the interactional discourse of Vehicle Inspection Officers and Drivers on major high ways in Abuja. Critical Discourse Analysis is a type of discourse analytical research that primarily investigates and exposes social problems. It focuses on social problems and the role discourse plays in the production, reproduction and resistance of such problems. CDA is based on the assumption that inequality, injustice and ideological dominance are reproduced and legitimated in language (Titscher et.al, 2000). It studies the manner social power, dominance and inequality are enacted, reproduced and resisted by text and talk in the social and political context (van Dijk, 2001). CDA gives a special attention to the issues of power, institution and ideology and how these are used in discourse to institute and perpetuate dominance. Domination, in most cases, comes about when there is a communicative encounter between a powerful group such as the Vehicle Inspection Officers and a powerless group such as the drivers.

A proper analysis of discourse using the approach of CDA takes context very crucial. No doubt, the understanding interlocutors have among themselves is largely generated by the context of verbal expressions. When such expressions are critically analyzed, language is viewed as a form of social practice (Wodak, 2011; Wodak and Brigitta, 2004). Language use is, no doubt, a social practice; it is a major concern of CDA. The language user has the ability to make a choice of the words that are considered a reflection of his ideology and fit for certain situations. This is very obvious when the communicative interaction is held between two 'unequal' groups. Essentially, this is considered "an effective means for polarizing power in society"( Ike-Nwafor, 2015, p.3). The reflection of this could obviously be seen in the choice of words of the VIOs and the drivers. Most scholars in the field of CDA have often believed that interlocutors' intention, ideology and thought processes are, most times, reflected in the choice of language they use. 
No doubt, the instrumental function of language cannot be overlooked. It is often reported that, in Abuja and indeed Nigeria, the men of the Vehicle Inspection Office (VIO), a privileged social group, demonstrate power and hegemony over erring drivers through a discriminatory and offensive use of language. This sometimes infringes on the rights of the drivers. Thus, it becomes necessary to critically analyse the discourse of these officers and drivers. The usefulness of this study lies in the fact that it would expose the 'abuse of power' displayed by the dominant group over the dominated group. Hopefully, the research will enable linguists and non-linguists to easily decipher the opaque agenda behind every word used by the VIOs in every encounter with drivers.

\section{METHODOLOGY}

This research employs a combination of descriptive and content analytical research design. It involves analytic survey that includes interview and participant observation. It is, essentially, a field research. The data used were majorly derived from oral interviews and personal observations (participant observation) within the space of four months (January April, 2019). The interlocutions between the officers of the VIO and drivers at major highways were carefully observed and transcribed. The interview was conducted in English with the officers of the VIO at their major offices and centres in Abuja: the VIO Computerized Vehicle Testing Centres at Kugbo-Nyanya axis, Katampe -Kubwa axis and Mabushi office.

For reasons best known to the officers in the office, they however could not divulge certain information to the researcher. The researcher therefore dwells so much on the data collected from motorists in three different highways in Abuja: the Nyanya-Keffi highway, the Zuba-Kaduna highway and the Gwagwalada -Lokoja highway. The interviews were carried out with the fined drivers stealthily, and not with the officers on the road. This is obviously because the officers were likely bound to adjust their conversation on the sight of a tape recorder at the road blocks for fear of being exposed. The researcher, at some time, interviewed the erring drivers immediately after their encounter with the VIOs. At some other times, the researcher made arrangements with some commercial drivers who are potential victims (going by the bad condition of their vehicles) by observing their conversation with the VIOs. The drivers were fully informed of this arrangement and their consent to include their ideas and comments in this research was properly sought. This kind of observation was carried out nine times on the three major highways. A total of 20 samples were collected from the three axes of the highways. Out of the number, 10 samples were critically selected, studied and transcribed. Library and research materials from the internet were also consulted.

The limitation faced in the adoption of this 'arranged system' borders on issues of change in the linguistic behaviour noticed among some drivers. The degree of this observer's paradox is however quite minimal and does not influence the linguistic phenomenon being observed by the researcher.

\section{LITERATURE REVIEW}

A good study in Critical Discourse Analysis is expected to focus on issues of power relations, ideology, dominance and inequality. Many researchers have, over the years, 
investigated these issues as expressed and legitimized in language in use (Wodak 2011). However, nothing much has been done so far on the verbal interaction between road users and the officials responsible for road safety in Nigeria.

Mele and Bello (2007)'s "Coaxing and coercion in roadblock encounters on Nigerian highways" is among the few research works on driver-officer verbal interaction that have investigated the use of language in social interactions. They investigate the verbal exchanges between drivers plying the highways of North-Eastern Nigeria and the security personnel in charge of the checkpoints. Using the approach of CDA, the study reveals the underlying relationship between coercion and social control which is clearly manifested in discursive power representation. The findings show that some "illegitimate dealings are perpetrated in seemingly innocent conversational exchanges, wherein illegal acts are discursively shielded" (p.438).

In their work, "Analysis of power and threat manifestation in the discourse of traffic police officers: A CDA perspective", Dastjerdi, Mehdi and Elham (2011) critically examine the manipulation of language by uniform men in a way that manifests the exercise of power and threat in social interactions. They examine the role of social status and discourse in relation to the choice of words used by the privileged social actors to manifest power and threat over the dominated social actors. The study focuses on the "illegitimate conversation" between traffic police officers and the drivers plying the Isfahan-Tehran highway in Iran. It was discovered, through the study, that the traffic police officers displayed power in their language. Their findings also show that there are some "illegitimate dealings" by the officers in carrying out their legitimate duty.

Issues of power in discourse have been very key and have, over the years, dominated scholarly works by many modern linguists. It is "the relational capacity that enables a social actor to influence, asymmetrically, the decisions of other social actor(s) in ways that favour the empowered actor's will, interests, and values" (Castells 2009,p.10). The display of power in discourse basically involves a verbal interaction between two interlocutors with one controlling and influencing the actions of the other. This, according to Fairclough (1989), has "to do with powerful participants controlling and constraining the contribution of non- powerful participants."'(p.38). Power is a concept that has been approached from many perspectives, with each producing diverse insights and meanings. The works of some theorists have shown that power takes different forms and that there are bases and resources that permit the exercise of power (Wartenberg 1990; Wrong 1997). While some have engaged themselves in exploring the complex relationship between the quantitative distribution of power, as well as the processes of social consent that legitimate various expressions of power. Others' concern is the examination of the changing ways power circulates throughout societies (Foucault, 1980). Indeed, the role of power in discourse cannot be overemphasized. Power influences people's behaviour and disposition when it is inherent in speech. It is described as "the capacity to exert interpersonal influence" (Brockeriede, 1971, p.313). The simple explanation of this is: if A exerts influence over B and gets him to do what, ordinarily, he (B) would not do, then, A has power over B. (Dahl, 1969). Power, in speech, gets people to act either in the right direction or in the wrong direction. When there is interplay of power and threat in discourse, actions are carried under duress and not by consent.

The Vehicle Inspection Officers, no doubt, wield institutional power. They command obedience from road users because they have obviously been mandated by the government 
to check vehicles' road worthiness. What makes drivers on the road to simply comply with the men of the Vehicle Inspection Office is power; an institutional power which must be obeyed by the drivers. The motorists, on few occasions, wield enormous power over the Vehicle Inspection Officers. This happens when the driver is a superior uniform man, either a military officer or a police officer.This institutional power is transmitted by speech: the interaction between the Vehicle Inspection Officers and the drivers.

Ideology is another salient phenomenon that shapes the language of many people. This notion was brought into limelight through the work of Karl Marx (1977). He uses ideology here to mean the ways in which society as a whole adopts the ideas and interests ofthe dominant economic class. It is the exercise of dominant and strong ideas over and above other ideas which are, in most cases, overlooked or shunned. Marx uses this framework to "explain howthe subordinate classes take exploitative relations of production for granted, as something solid and unchangeable" (Stoddart, 2007, p.191). Campbell and Kean consider ideology to be "those modes of feeling, valuing, perceiving and believing that exist within and inform our everyday lives and connect us to wider structures of power in society in ways that contribute to the maintenance and reproduction of social power" (p.9). Ideology in discourse is a key factor that must be carefully considered in any CDA exercise. It is a veritable tool used by various social institutions to sustain the position of the dominant class in every communicative encounter with the dominated class. Ideology, no doubt, is "pervasively present in language" and this is "taken for granted as matters of common sense" (Fairclough, pp.3, 77). Ideology models the communicative interaction between the VIO and drivers on the highways with each trying to maintain or suppress a dominant ideology.

\section{THEORETICAL UNDERPINNING}

This study, being a CDA exercise, is basically grounded on Fairclough's (1995) Ideological Discursive Formations (IDF) and Fairclough's (1989) Members Resources, with insights from van Dijk's $(1998,2001)$ social cognitive notion of Positive Selfpresentation and Negative Other-presentation. Fairclough presents IDF as a notion that describes a dominant discursive ideology or belief inherent in discourse which is socially acceptable and 'naturalized' as a norm. According to him, "there is usually one IDF which is clearly dominant..." in every speech situation, and that one important characteristic of this dominant IDF “is the capacity to 'naturalize' ideologies, i.e. to win acceptance for them as non-ideological 'common sense'..." (p.27).This dominant IDF shapes, and is in turn shaped by discourse. A critical look at this notion shows that speech and behaviour are ideologically motivated. The goal of CDA, therefore, is to "denaturalize" this dominant IDF, hence the need for a critical approach (p.27).

It can be seen from the explanation above that contentions between forces within social institution mostly come about as a result of the need to maintain or impose a dominant IDF by the dominant social group as well as replacing or suppressing an existing IDF by the dominated social group. In every communicative encounter between the Vehicle Inspection Officers and drivers on the road, there is always a clash of ideology and interest among them. The dominant IDF inherent in the interlocution between them appears in two ways: on one hand, the drivers hold a popular notion that the VIOs are a wicked and heartless 
group. On the other hand, the VIOs see the drivers as a recalcitrant and rebellious group who would always flout institutional order and laws.

Fairclough's (1989) Members Resources (MR) is another major principle this research, as well as its analysis, is grounded. According to him, the MR is the notion people have in their heads and draw upon when they produce or interpret texts. This includes their knowledge of language, representations of the natural and social worlds they inhabit, values, beliefs, assumptions and so many other elements of context. He believes that the MRs are cognitive because they are in people's head. The illustration of this basic pragmatic principle is very obvious: when an utterance is made, people use contextual cues to attach meaning to what is said. Contextual cues like the hearer's or reader's knowledge of the speaker or writer, his social status and the circumstances that surround the utterance are key factors that help to decipher the invested ideology in a text. For instance, it takes the internalized MR of a driver to understand what a VIO means when he says "if you don't know what to do, we would take you to the office."

Teun van Dijk's (2001) Socio Cognitive approach to Critical Discourse Analysis simply reveals that the meaning an individual makes out of a text is the product of his socialcognitive experiences. He avers that a text within a social setting influences the cognitive outcome of such a text on hearers or readers. van Dijk's notion is that, for an individual to properly appreciate a text or discourse in society, it is very necessary for such an individual to "analyze the cognitive and social factors, conditions, constraints, or consequences of such textual structures and, indirectly their economic, cultural and historical embedding" ( p.176). For instance, if an erring driver pleads with a VIO to 'double check' his (the driver) vehicle papers, the VIO does not need any further explanation before he understands what the driver actually means. The communicative interaction between the VIOs and the drivers is, indeed, a social representation. VanDijk also believes that discourse is used to polarize social representations. He calls this "Positive Self-presentation and negative Other presentation" (103). According to him, discourse is used in such a way that 'our' good things and 'their' bad things are emphasized while 'our' bad things and 'their' good things are de-emphasized. This is evident in the discourse of the VIO and drivers.

\section{DATA ANALYSIS AND DISCUSSION}

CDA, by nature, employs diverse methods of analysis. According to van Dijk (2001), "CDA should be essentially diverse and multidisciplinary" (p.96). A good CDA should adopt a combination of different techniques and levels of analysis. In CDA studies, a text is considered as a representation of the sender. That is to say that, what one says or does is the interpreter of who he really is (Azeez, 2016, n.pag.).One may have full control of the words he uses but the meaning derived from such words is certainly beyond his control. This analysis, therefore, shall adopt a 'critical' method in analyzing the sampled texts which shall, henceforth, be referred to as extracts. The word 'Critical' here implies highlighting connections and causes, which are hidden or not obvious (Atkins, 2002). This requires the analyst to investigate the invisible relations between interlocutors expressed in language. This method is adopted to unearth the power relation and ideology inherent in the discourse of Vehicle Inspection Officers and drivers. The analysis is essentially done based on Fairclough's notions of IDF and MR as well as van Dijk's social cognitive notion of Positive Self-presentation and Negative Other-presentation. The data were analysed based 
Discursive Construction of Language between the Vehicle Inspection Officers and Drivers in Abuja

on two major topics: Discursive Construction of Power and Ideology and Discursive Construction of Self (us) and Others (them).

\section{Discursive Construction of Power and Ideology}

Power and ideology are often manifested in the conversations between the VIOs and drivers on the road. Extracts 1-5 are based on lexical choices of the officers and drivers to convey power and ideology. This is manifested here to display social status. In this discussion, a special attention would be given to the manifestation of dominant IDFs that have the capacity to naturalize other ideologies. The manifestation of social status in the utterance of the VIOs and the drivers shall be explored.

\section{Extract 1}

1. Driver: Officer, how are you?

2. VIO (ignores the compliment and inspects the vehicle): Get down from the car and prove to me that all is well with your tail light.

3. Driver: I know it has been broken but...

4. VIO: But what?

5. Driver: I think I should be given the opportunity to explain.

6. VIO: Explain what? There is nothing to explain when you drive a car without the tail light. Ok, how do we help you?

7. Driver: Now you are talking.

\section{Analysis and Discussion}

One of the major offences in road traffic regulation is driving a car without a functional tail light (brake light). The driver in the above extract commits the same offence. Sometimes, however, the officers of the Vehicle Inspection Office display their superior status by directly or indirectly downgrading the status of the drivers in the words they (officers) use. In the conversation above, the driver, in (1), greets the officer in a courteous manner but the officer intentionally ignores it. He, instead, uses authoritative statement to point out the driver's offence. Also, in (4 and 6), the officer maintains a dominant tone and could not allow the driver to talk. The officer has, by so doing, shown that he has the ultimate power to control the speech of the driver. Here, what matters is the officer's dominant IDF and not the driver's ideology. The officer's utterances create a mental model that he is in charge and that his ideology has to be respected. The internalized MR in the Officer's statement in (6):(... Ok, how do we help you?) is very obvious. By that statement, the driver already knows what to do to get himself out of the net of the VIO without necessarily paying the legally recognized fine in the office.

\section{Extract 2}

1. VIO: Park well

2. Driver (after parking at the pedestrian path of the road): Officer what is the problem?

3. VIO: Hand over your car keys.

4. Driver: Could you please let me know what the offence is?

5. VIO: By the time I delay you here, you will know that we are not here for a joke.

6. Driver: I will not give you the keys if you don't tell me my offence. 
7. VIO: You wrongly overtook a vehicle at that sharp bend and you are here bragging. Give me one reason why you should not be punished?

8. Driver: How does that concern you? Officer, it is not your duty to stop vehicles for overtaking. I'm a police officer (displays his official ID card).

9. VIO: Esprit de corps (he salutes). Matter... closed!

\section{Analysis and Discussion}

It is, no doubt, a fact that when two unequal social actors interact in any communicative situation, language is often used by the 'superior' actor to manifest social status. Social status is mostly displayed by the dominant group in an encounter with the dominated group to either show a sense of superiority or to intimidate the dominated group. This is made possible by the instrument of institutional power. Most times, the men of the Vehicle Inspection Office use the resources of power and authority at their disposal to institute their dominant ideology in their encounter with their civilian counterparts. This is obviously manifested in the action and utterances of the VIO in the above text. As can be seen from the conversation, the driver seeks to know why he is asked to stop but the VIO, instead of telling the driver his offence, uses delay tactics to display his power over the driver. Unfortunately, the VIO does not know that the driver, who turns to be a police officer, wields much more power. The VIO's authoritative use of the command statement: "Hand over your car keys" in (3), clearly shows the manifestation of institutional power. On the other hand, the driver's statement, in (8), shows a superior institutional power and knowledge of the law. This clearly reveals the driver's show of a superior social status.

The VIO, no doubt, has the legitimate power to delay and sanction the driver whenever the latter commits an offence. However, we see an illegitimate use of power in the action of the VIO. First, he unduly delays the driver without telling him (the driver) the offence he committed. Also, it is outside the jurisdiction of the VIO to punish drivers for overtaking on the road. That, indeed, is the duty of the Federal Road Safety Corps. The VIO illegitimately delays the driver by employing the tactic of 'blame heaping' which, indeed, is a method by which most uniformed men and security personnel use guilt-triggering expressions against drivers with the intention of eliciting feelings of guilt (Mele\& Baba, 2007).

The VIO later succumbs to a greater institutional ideology- the dominant IDF of the driver (the police officer) which has the capacity to win acceptance from the VIO.

\section{Extract 3}

1. VIO (to a truck driver): Park well.

2. Driver: Any problem sir?

3. VIO: What are you carrying?

4. Driver: Paints.

5. VIO: Let me see your waybill.

6. Driver (hands over the documents): Check them. Everything is alright. I think I should be going now.

7. VIO: Allow me to do my job. It would take time for me to unload and check your vehicle.

8. Driver: Ok. Can you double check my document so I can go now?

9. VIO: Now you are talking. 


\section{Analysis and Discussion}

In this extract, there is no accusation of an offence. This gives the driver the audacity to speak with a confident tone. According to Mele and Baba, such cases of confidence by some drivers "are indicators of a kind of resistance by some drivers and an attempt to challenge the authority and power" (p.442) of the traffic officers. The confident tone of the driver, however, is of no use here as the officer uses his power to control the conversation. In this conversation, power is illegitimately exercised by the officer to display a superior status. Such cases of illegitimate use of power by the officer are seen by many drivers as institutional representations. This gives an impression of corrupt practices by the men of the Vehicle Inspection Office. It is obvious, in the conversation, that the officer gives indirect signals to demand money from the driver. In (7), he mentions time parameter and that implies that the driver must wait for a long time for his truck to be unloaded for the officer to inspect. A typical Nigerian driver does not have the patience to wait that long. The mental model created by the officer's statement here is that the driver would definitely suggest an alternative means of evading the hurdle. The MR that reflects in (8) is clearly understood by the officer, hence the response in (9). This clearly shows an abuse of power on the part of the VIO who is supposed to be a custodian of law on the highway.

\section{Extract 4}

1. VIO: Did you check your windshield before leaving the house?

2. Driver (apologetically): Yes, I did but please pardon me to manage it today. I will replace it tomorrow.

3. VIO: I'm only doing my job to protect your life from danger.

4. Driver: Yes I know, but can we talk here? I'm in a hurry.

5. VIO: No, we can't talk. I'm not hungry. I think you need to be reported to the office.

\section{Analysis and Discussion}

Here in this extract, we see a domineering ideology towering over and above a dominated ideology. This is done to show a superior social status. The officer, in the conversation above, uses words laden with power to demonstrate his status. Of course, he is mandated by law to ensure that vehicles are fit to use the road. He wastes no time in demonstrating this in (3). The driver, on the other hand, tries in vain to display an ideology in (4). He displays an internalized MR which the officer quickly deciphers. Unfortunately for the driver, however, the officer's ideology, in (5), supersedes his (driver) own ideology. This honest act by the officer, in this extract, is commendable. Some officers' interactions with drivers on the road create the impression that they (the officers) can easily be 'settled' on the road when the drivers cannot afford to be delayed or forced to pay fine. That, of course, is the mental model that motivates the driver, in this extract, to offer the bribe. This, indeed, is a case of legitimate use of power to correct social ills and malpractice. 


\section{Extract 5}

1. VIO (to a driver of a good-looking range rover jeep): What is wrong with the sound of your horn? I can't hear it.

2. Driver: It just suddenly stopped working now. I guess it's a mechanical fault.

3. VIO: As a driver, you should know the right thing to do. I hope you know that your horn must be heard from a distance of 60 meters.

4. Driver: Yes, I know but I told you it just developed this fault. Haba! If I miss my flight you will dearly pay for it.

5. VIO: Who are you? I can't be intimidated by your car. I will show you. Oya, submit your keys to me. I'm moving you to the office.

6. Driver (beckons on two tall hefty men in the vehicle): My guys are coming to deal with you.

7. VIO: Just go. I don't have your time.

\section{Analysis and Discussion}

There seems to be a clash of superiority of status between the officer and the driver in the extract above. The conversation started on a lighter note. The officer uses a matter-of-fact tone to explain what the driver should know. The driver, in his response in (4), demonstrates that he belongs to a high social class and feels he should not be treated like other less important persons in society. The driver's statement: "If I miss my flight.....",clearly displays an internalized MR in the minds of both the officer and the driver. This common MR is that the driver is rich, just because he drives an expensive car.This, of course, is a common phenomenon in the Nigerian social context. Many times, people judge others' riches by the nature of cars they (others) use, not minding who really owns such a car and how the owner makes his money. The driver in the above extract, probably, wants to be respected as a VIP due to the fact that he uses a very expensive car. The officer, on the other hand, demonstrates that he is of a higher social status. By the virtue of the social and institutional power the officer wields, he shows, in (5), that he has a superior status than the driver. This, unfortunately, does not matter here. The driver seems to have a superior power, which is rather illegitimate, over the officer. By this, the ideology of the officer does not count; rather, the driver's dominant ideology prevails. The mental model construed by the appearance of the hefty men (who, obviously, are thugs) makes the officer back out. The driver, here, exercises an illegitimate power to display a 'superior' status.

\section{Ideological Discursive Construction of Self (us) and Others (them)}

This analysis is essentially based on the lexical choice of the officers. In this analysis, the reason for the careful choice of words by the officers to display their institutional ideology will be shown. The discussion is based on van Dijk's (2001) "positive self-presentation and negative other presentation" (p.103). This is a case of an ideologically biased discourse which polarizes the representation of "us" (in-groups) and "them" (out groups). Here, discourse is used in such a way that 'our' good things and 'their' bad things are emphasized while 'our' bad things and 'their' good things are de-emphasized. Extracts 6-10 are based on this analysis. 


\section{Extract 6}

1. VIO (to a private driver who is obviously a learner): Hello Madam Learner, where are you driving to?

2. Driver: To the Federal Secretariat. Is there any problem?

3. VIO: Not at all, just that I would like to see your Learner's Permit.

4. Driver: What do you mean? Can't you see the affixed plates displaying the letter ' $L$ ' on the front and rear of the car?

5. VIO: Madam, I need to see your permit.

6. Driver (brings out a paper from her car): This is the certificate from the driving school.

7. VIO: This is not a Learner's Permit. This is just a paper given to you. A permit must be given to you from a certified driving school. You attended a roadside driving school which we do not certify. Before a driving school begins training of drivers, it must be certified by us. Many so-called driving schools are out there without our approval. This is why we recommend that before you attend a driving school, you need to seek professional advice from us, but you will not do that. When you go ahead and attend a driving school that does not have approval from us, you are on your own. They are there to collect your money.

\section{Analysis and Discussion}

In the extract above, we see the deployment of negative lexical items for driving schools that are not 'certified' by the Vehicle Inspection Office. Negative expressive phrases like "just a paper", "roadside driving school" and "so- called driving school", in (7), are willfully used to present the driving schools that do not have approval from the Vehicle Inspection Office in a bad light. This presupposes that drivers who attend those unauthorized driving schools are not good drivers. The officer uses lexical items like "we do not certify", "it must be certified by us", "our approval", "professional advice from us", and "approval from us", in (7), to project his office in a positive light. This ideologically biased discourse is intentionally used to polarize the representation between 'us' (in- group) and 'them' (out- group).This ideological inequality is further heightened by the use of 'we', 'us', 'you and 'they' to show that the officer and the other groups (unauthorized driving schools and drivers) belong to different social and ideological positions.

\section{Extract 7}

1. VIO: Pullover

2. Driver: Is there any problem?

3. VIO: Mr. man, your front tyre needs to be changed.

4. Driver: What is the problem with this tyre? Check it well. It's ok.

5. VIO: You don't teach me my work. We are here to protect you from danger. You would not appreciate us now until the unexpected happens.

\section{Analysis and Discussion}

We could see the projection of self-image and self-glorification in this extract. The discourse of the Vehicle Inspection Officer above depicts self glorification. The officer projects the positive image of the office he represents. The statement, "you don't teach me my work" in 
(5), presents the officers as experts who have been well trained in their job. Also, the officer demonstrates that the VIO also engage in humanitarian activity when they tell drivers what to do to be safe on the road. The statement, "we are here to protect you from danger", also in (5), clearly portrays that. The statements of the officer present a mental model of self-glorification of the Vehicle Inspection Office.

\section{Extract 8}

1. VIO: Your Road Worthiness Certificate needs to be renewed. Are you aware?

2. Driver: I'm aware but I don't have the money to do that now, but if I work this week and next week I should be able to fix my car and apply for a new one.

3. VIO: This is the problem with you drivers. When we honestly advise you to do the right thing, you hate us. Just take a look at the back tyre of your car. What if the unfortunate happens before next week? Look, we are here to safeguard your life and the lives of other road users. No matter how you insult us, we would not relent in doing our good job.

\section{Analysis and Discussion}

It is obvious, in the extract above, that the lexical items used are intentional. The choice of words like "problem" which is associated with "you drivers", "you hate us" and "you insult us" are ideological constructs that obviously emphasize the negative presentation and representation of the drivers who are painted in negative light. The resistance from some drivers is considered by the officer, in (3), as a "problem" with the drivers. The implication of his assertion is that the drivers insult and castigate them whenever they (officers) try to do their legitimate duty. The mental model being construed here is that most motorists plying the Abuja roads and its environs believe that the men of Vehicle Inspection Office are heartless and wicked. The Vehicle Inspection Officer, on the other hand, emphasizes their good aspect by putting the following words together: "we honestly advise you to do the right thing", "we are here to safeguard your life and the lives of other road users" and "we would not relent in doing our good job". The above ideologically biased discourse of the officer leaves us with no doubt that they (officers) make us believe that they are only doing their legitimate job and would continue to do that irrespective of the unfavourable criticisms from drivers and the general public. By this, they present themselves as good by de-emphasizing their flaws while denigrating the action of drivers as bad which is rather emphasized.

\section{Extract 9}

1. Driver: What is the problem?

2. VIO: You wrongly overtook a vehicle on the traffic

3. Driver: Is that why you stopped me?

4. VIO: You think we are on the road just to punish you? We are doing our job for your good. We are taking you to the office.

5. Driver: I'm sorry. 


\section{Analysis and Discussion}

There is an ideology of self-glorification in the extract above. The Vehicle Inspection Officer carefully selects his words to positively present his office as doing their legitimate duty for the benefit of all. In doing that, he goes ahead to emphasize the wrong doings of the driver. By using the lexical items like "You think we are on the road just to punish you?" in (4), the officer creates a kind of mental model of what drivers think and talk about the Vehicle Inspection Officers. It is, indeed, very rare to see motorists on Abuja roads commending the men of the Vehicle Inspection Office. Most motorists see the action of the road officers as wicked and callous. They feel the officers are on the road to punish them (the motorists). This is evident in their conversation above. The driver does not believe it is a road traffic offence to overtake another vehicle on the traffic. He, therefore, questions the reason why he was stopped by the officer when he says "Is that why you stopped me?"

A critical study of the VIO-drivers discourse shows that when two 'unequal' social actors with divergent ideologies interact, there tends to be an imposition of a dominant ideology by the dominant actor. In the conversation above, the officer succeeds in imposing his dominant ideology, which is accompanied by threat, when replying the driver. The driver is thus forced to succumb to that ideological pressure and apologizes accordingly.

\section{Extract 10}

1. VIO: Sir, may I have your papers, please.

2. Driver (hands over the papers): Officer I'm sorry, my vehicle was just brought into the country about two months ago. I'm in the process of registering it.

3. VIO: You are aware that the maximum period for use of foreign number plate in Nigeria is 30 days, and yet you have been using this number plate for over two months now. Your action is an intentional breach of law and an act of gross misconduct.

4. Driver: Please pardon me just for this week. The papers would be ready by next week.

5. VIO: Then you wait and do what is right. Sir, I understand you are well enlightened and you should know better. You can now see how wrong you are when many of you criticize us out there for doing the right thing.

\section{Analysis and Discussion}

The action of the motorist, in the extract above, is defined in negative terms and considered legally reprehensible. The Federal Road Safety Corps gives a deadline of thirty days for the use of foreign number plates on Nigerian roads. As noted earlier, the Vehicle Inspection Office works together with the Federal Road Safety Corps, in this instance, to ensure that roads and vehicles are in good condition. In the extract, the Vehicle Inspection Officer chooses some lexical items like "intentional breach of law" and "gross misconduct" which are ideological concepts related to the Nigeria Highway Code of the Vehicle Inspection Office. The choice of those words is made to ideologically portray a negative "other" presentation of the driver. Similarly, in the statement, "how wrong you are when many of you criticize us out there for doing the right thing" in (5), the lexical choice shows negative other presentation of "them" and positive self-presentation of "us". This creates a mental model that the Vehicle Inspection Officers and motorists are always at loggerheads over road related offences. The officer paints a negative picture of the motorists and considers them to be "wrong" while presenting themselves (the officers) as doing the "right thing." 


\section{CONCLUSION}

This study has so far investigated the discourse of Vehicle Inspection Officers, as they interact with drivers on Abuja highways, in a manner that reveals the reason behind the manifestation of power and ideology. The study is not only interested in the linguistic analysis of the text but also probes deeper into the discursive strategies for the enactment and resistance of social inequality and power. The study adopts the concept of Critical Discourse Analysis with a special focus on Fairclough's principles of Ideological Discursive Formations (IDF) and Members Resources, drawing insights from van Dijk's social cognitive notion of Positive Selfpresentation and Negative Other-presentation.

The study reveals that the Vehicle Inspection Officers specially choose their words to basically institute a dominant ideology. The officers employ different strategies in words and actions to send coded signals to the drivers in order to make the drivers comply to do their (officers) bidding This tactic is, indeed, working out for the officers because most drivers cannot afford to have their vehicles moved to the VIO office because they are aware of the implications. By that, the mental models of the drivers are gainfully controlled by the officers on the road. Some 'powerful' drivers, on the other hand, also deploy the use of language to threaten the officers who may be doing their legitimate job. In some of the analyzed extracts, the ideologies of the drivers do not matter at all in the face of a strong and dominant ideology of the officers. It has, thus, been discovered that the speech behaviour of the officers towards the drivers, and vice versa, is largely conditioned by their dominant Ideological Discursive Formations. These IDFs are used by them to display a superior social status.

It is also discovered, from this study, that ideology is deployed, in words, as a means of enacting negative other presentation through the use of carefully selected negative lexical items to emphasize the negative aspects of others. This strategy is employed by the officers to counter or debunk the claims of most drivers that the Vehicle Inspection Officers are wicked and heartless. In the same vein, the study also shows that ideology can also be used as a strategy for self-glorification. It is revealed that the Vehicle Inspection Officers, in their interaction with drivers, use positive words to self-promote themselves and paint the institution they represent in a positive light.

It is therefore recommended that language researchers and the general public should pay more attention to the use of language and the role language is made to play in any communicative encounter between interlocutors. This will, no doubt, make them to watch out for cases of power, ideology and dominance inherent in the language of a 'powerful' and dominant group.

\section{REFERENCES}

Amberg, J \& Deborah J. (2009). American English: history, structure, and usage. Cambridge University Press.

Atkins, A. ( 2002). Critical discourse analysis: A letter to expatriates from theRt. Hon. Sir Norman $\begin{array}{llll}\text { Fowler } & \text { M.P. } & \text { fPDF } & \text { Retrieved }\end{array}$ fromhttps://pdfs.semanticscholar.org/7b0b/d9b0642f55caa1ffa46d7be18b7698b57289.pdf 
Discursive Construction of Language between the Vehicle Inspection Officers and Drivers in Abuja

Azeez, T. (2016, June 8). ENG 706: Discourse analysis [Lecture note]. Masters Class, University of Abuja.

Brockeriede, W. (1971). Dimensions of the concept of rhetoric. In Johannesen,R.L. (ed.), Contemporary theories of rhetoric: Selected reading (pp.311-326). Harper and Row.

Campbell, N. \& Kean, A. (1997). American cultural studies: An introduction to American Culture. Routledge.

Castells, M. (2009). Communication power. Oxford University Press.

Dahl, R. (1969). The concept of power. In Roderick B, et al.(eds.), Political power: A reader in Theory and research. The Free Press.

Dastjerdi, H., Mehdi L. \&Elham, M. (2011). Analysis of power and threat manifestation in the Discourse of traffic police officers: A CDA perspective. Journal of language teaching and research, 2(1), 255-260.

Fairclough, N. (1995). Critical discourse analysis: The critical study of language. Longman.

Fairclough, N. (1989). Language and power. Longman Group.

Foucault, M. (1980). Power/knowledge: Selected interviews and other writings. Vintage Books.

Gatcho, A. R. G., \& B. Ramos, Jr., E. T. (2019). Stylistic analysis of Philippine English and Singaporean English in automotive review articles. International Journal of Language and Literary Studies, 1(1), 1-13. https://doi.org/10.36892/ijlls.v1i1.23

Ike- Nwafor, N. G. (2015). Critical discourse analysis of selected political campaign speeches of gubernatorial candidates in the South Western Nigeria 2007- 2014. (Doctoral dissertation, University of Nigeria Nnsuka, Nigeria). Retrieved from https://oer.unn.edu.ng/

Marx, K. (1977). Capital: A critique of political economy.(B. Fowkes,trans.).Vintage Books.

Mele, M., \& Baba, M. (2007). Coaxing and coercion in roadblock encounters on Nigerian Highways. Discourse and society, 18(4), 437-454.

Osisanwo, W.(2003). Introduction to discourse analysis and pragmatics. Femolus-Fetop Publishers.

Owojecho, G.A. (2017). Critical discourse analysis of Vehicle Inspection Officers and drivers' interlocution in Abuja- FCT. (Master's thesis, University of Abuja, Abuja, Nigeria).

Stoddart, M. (2007). Ideology, hegemony, discourse: A critical review of theories of Knowledge and power. Social thought and research, 191-225.

Titscher, S., et al. (Eds.). (2000). Methods of text and discourse analysis. Sage Publications Ltd. 
Van Dijk, T.(2001a). Critical discourse analysis. InSchiffrin. D., Tannen, D. \& and Hamilton, H. E. (eds.),Handbook of discourse analysis (pp. 352-71).Blackwell Publishers.

Van Dijk, T. (2001b).Multidisciplinary CDA: A plea for diversity. In Wodak, R., \& Meyer, M. (eds.), Methods of critical discourse analysis (pp. 95-119). Sage Publications Ltd.

Van Dijk, T. (1998). Ideology: A multidisciplinary approach. Sage Publications.

Wartenberg, T. (1990). The forms of power: From domination to transformation. Temple University Press.

Wodak, R. (2011). The discourse historical approach. In Wodak, R., \& Meyer, M.(eds.), Methods of critical discourse analysis (pp. 63-94.). Sage Publications Ltd.

Wodak, R. and Brigitta B. (2004). Approaches to media texts. In John, D., et al. (eds), Handbook of Media Studies, (pp.108-123). Sage Publications Ltd.

Wrong, D. (1997). Power: Its forms, bases, and uses. Transaction Publishers.

\section{AUTHOR'S BIO:}

Godwin AyigboOwojecho is a Teaching/ Research Assistant (part-time lecturer) in the Department of English, Institute of Education, University of Abuja, Nigeria. He earned his Master's degree in English Language from the University of Abuja. His research interests include Critical Discourse Analysis, Pragmatics and Sociolinguistics. He is the Coordinator/ Principal Consultant of Sureki Global Editors, Nigeria. 